\title{
Correction to: Artificial neural network based high dimensional data visualization technique for interactive data exploration in E-commerce
}

\author{
Cong $\mathrm{Wu}^{1,2}$ - Hongxin $\mathrm{Li}^{1}$ - Jiajia Ren ${ }^{1,3} \cdot \mathrm{K}$. Marimuthu ${ }^{4}$. \\ Priyan Malarvizhi Kumar ${ }^{5}$
}

๑) Springer Science+Business Media, LLC, part of Springer Nature 2021

\section{Correction to: Annals of Operations Research https://doi.org/10.1007/s10479-021-04436-y}

Author affiliations were incorrectly communicated during article typesetting and needs to be read as:

1. Second author's family name is "Li"' and the given name is "Hongxin", and affiliations to be read as:

School of Management Science and Engineering

Dongbei University of Finance and Economics

Dalian, 116023, Liaoning, China

Fourth author Marimuthu Karuppiah affiliations to be read as

Department of Computer Science and Engineering,

SRM Institute of Science and Technology,

Delhi NCR Campus, Modinagar, Ghaziabad, Uttar Pradesh 201204, India.

Original article has been updated.

The original article can be found online at https://doi.org/10.1007/s10479-021-04436-y.

Extended author information available on the last page of the article 
Publisher's Note Springer Nature remains neutral with regard to jurisdictional claims in published maps and institutional affiliations.

\section{Authors and Affiliations}

\section{Cong $\mathrm{Wu}^{1,2}$ (D) Hongxin $\mathrm{Li}^{1} \cdot$ Jiajia Ren ${ }^{1,3} \cdot \mathrm{K}$. Marimuthu ${ }^{4}$. Priyan Malarvizhi Kumar 5}

$凶$ Cong Wu

wucongdufe@163.com

Hongxin $\mathrm{Li}$

hongxinli100@126.com

Jiajia Ren

renjiajia@hnuahe.edu.cn

K. Marimuthu

kmarimuthu@ieee.org

Priyan Malarvizhi Kumar

P.Malarvizhikumar@ieee.org

1 School of Management Science and Engineering, Dongbei University of Finance and Economics, Dalian 116023, Liaoning, China

2 Institute for Optimization and Decision Analytics, Liaoning Technical University, Fuxin 123000, Liaoning, China

3 College of Logistics and E-Commerce, Henan University of Animal Husbandry and Economy, Zhengzhou 450044, Hennan, China

4 Department of Computer Science and Engineering, SRM Institute of Science and Technology, Delhi NCR Campus, Modinagar, Ghaziabad, Uttar Pradesh 201204, India

5 Department of Computer Science and Engineering, Kyung Hee University, Seoul, South Korea 